\title{
Tumor escamoceluar pulmonar bien diferenciado que se presenta con cavitación, infiltración de reja costal y fístula a pared del tórax
}

\author{
Well differentiated squamous cell carcinoma of the lung \\ that presented with cavitation, infiltration of the rib cage, \\ and fistula to the chest wall
}

Camilo AndrÉs Medina, MD. ${ }^{(1)}$; Luz Fernanda SuA, MD., PhD. ${ }^{(2)}$; LILIANA Fernández T. MD. ${ }^{(3)}$

\begin{abstract}
Resumen
El cáncer escamocelular de pulmón es una patología de prevalencia alta en el mundo, en especial en personas fumadoras. Típicamente afecta la vía respiratoria de conducción y la variedad papilar tiende a invadir los bronquios. Los síntomas más frecuentes son causados por el efecto mecánico en la vía aérea inferior e incluyen tos, hemoptisis y neumonías recurrentes. Se expone el caso de un paciente con un tumor escamocelular bien diferenciado de pulmón con comportamiento atípico y agresivo, compromiso de la vía aérea, la pleura, la reja costal y los tejidos blandos del tórax hasta la piel; además de sus manifestaciones clínicas, estudios diagnósticos y la revisión de la literatura al respecto. El carcinoma escamocelular pulmonar forma parte de los tumores de células no pequeñas del pulmón. Es una neoplasia maligna típicamente productora de queratina que se diferencia por la histología y los estudios de inmunohistoquímica tiene una prevalencia mayor en los fumadores o exfumadores los cuales representan el $90 \%$ de los casos, el diagnóstico oportuno mejora la supervivencia y calidad de vida de los pacientes afectados. En este oportunidad presentamos un caso con comportamiento atipico que nos enseña a incluirlo en el diagnóstico diferencial de lesiones que comprometen la pared del tórax.
\end{abstract}

Palabras clave: pulmón, invasión, escamo-celular, pared torácica.

\begin{abstract}
Squamous cell cancer of the lung is a common condition at the worldwide level, especially in smokers. It typically affects the conduction airway, and the papillary variety tends to invade the bronchi. The most common symptoms are caused by the mechanical effect on the lower airway, and include cough, hemoptysis, and recurrent pneumonia. We present the case of a patient with a well differentiated squamous cell tumor whose behavior was atypical and aggressive, with involvement of the airway, the pleura, the rib cage, and the soft tissues of the chest up to the skin. We also describe its clinical manifestations, diagnostic studies, and review the literature. Squamous cell carcinoma of the lung is one of the non-small-cell lung carcinomas. It is a malignant neoplasm that typically produces keratin, and is discriminated by histological and immunohistochemical studies. Its prevalence is higher among smokers and ex-smokers, who represent $90 \%$ of cases. Timely diagnosis improves the survival and quality of life of affected patients. In this article we present a case with atypical behavior; it teaches us to include this condition in the differential diagnosis of injuries compromising the chest wall.
\end{abstract}

Keywords: lung, invasion, squamous cell, chest wall.
${ }^{(1)}$ Residente de Medicina Interna, Funda-
ción Valle del Lili. Facultad de Ciencias
de la Salud, Universidad ICESI. Cali, Co-
lombia.
${ }^{(2)}$ Anatomía Patológica y Patología Clíni-
ca, Departamento de Patología y Medicina
de Laboratorio, Patología pulmonar. Cien-
cias Biomédicas. Línea de investigación
Biomédica en Tórax, Fundación Valle del
Lili. Profesora Clínica Asistente, Facultad
de Ciencias de la Salud, Universidad Icesi.
Cali, Colombia.
(3)Medicina Interna, Neumología, Neumo-
logía Intervencionista, Línea del Investi-
gación Biomédica en Tórax, Fundación
Valle del Lili. Profesora Clínica Asociada,
Facultad de Ciencias de la Salud, Univer-
sidad Icesi. Cali, Colombia.
Correspondencia: Liliana Fernández T.,
correos electrónicos: lfernandez@ffcvl.org,
lilianafernandeztrujillo@gmail.com
Recibido: 15/08/16. Aceptado: 13/09/16. 


\section{Introducción}

El cáncer de pulmón es uno de los más frecuentes del mundo y es la neoplasia con mayor tasa de mortalidad. Tiene una relación causal ampliamente comprobada con el tabaquismo, el cual constituye el principal factor de riesgo y está implicado hasta en el 80 al $90 \%$ de los casos, principalmente entre fumadores activos. Otros factores de riesgo incluyen exposición ocupacional a asbestos, arsénico, níquel, hidrocarburos aromáticos policíclicos, entre otros elementos usados por ejemplo en la industria de refinación del metal al igual que la radiación ionizante (1). Sin embargo, como en otras patologías, la combinación de factores medioambientales con individuos genéticamente susceptibles da una explicación más racional al problema ya que no todos los fumadores desarrollan cáncer y existen una minoría de casos en personas que nunca estuvieron expuestos al cigarrillo (2). La incidencia es mínima por debajo de los 40 años y aumenta notoriamente hasta los 80 años para después disminuir nuevamente (3); datos similares se dan en nuestra población según el Registro Poblacional de Cáncer de Cali (RPCC).

El termino cáncer pulmonar se usa para designar los tumores derivados del epitelio de las vías respiratorias (bronquios, bronquiolos y alveolos). Los mesoteliomas, los sarcomas y los linfomas son diferentes de los cánceres epiteliales pulmonares. La Organización Mundial de la Salud (OMS) clasifica los tumores epiteliales de pulmón en cuatro grandes tipos histológicos que agrupan el $90 \%$ de las neoplasias a este nivel: carcinoma pulmonar de células pequeñas o microcítico y el de células no pequeñas o no microcítico que incluye: adenocarcinomas, carcinoma escamocelular o epidermoide y carcinoma de células gigantes o macrocelular. El 10\% restante lo componen carcinomas indiferenciados, carcinoides, tumores de glándulas bronquiales (quísticos adenoides y mucoepidermoides), entre otros más raros (4).

El carcinoma escamocelular o epidermoide fue el tipo histológico más frecuente de cáncer pulmonar hasta mediados de 1980. No obstante, con la disminución del consumo de cigarrillo en las décadas más recientes y los cambios en los procesos de elaboración de la industria tabacalera incluyendo el uso de diferentes tipos de filtros, el adenocarcinoma ha pasado a ser el tipo de cáncer pulmonar más común con hasta el $50 \%$ de los casos. El diagnóstico histológico de carcinoma escamocelular debe sospecharse cuando hay producción de queratina en las células tumorales y desmosomas intercelulares que generan puentes entre ellas, clásicamente vinculado con el antecedente de tabaquismo, En ausencia de estas, el diagnóstico puede establecerse mediante inmunohistoquímica con marcadores como p40, p63, CK5/6. Hasta el 80\% de los tumores escamocelulares se origina en las porciones proximales del árbol tráqueo-bronquial mediante un proceso secuencial de metaplasia escamosa, displasia, carcinoma in situ y progresión de la lesión. Algunas de estas pueden mostrar extensa necrosis central con formación de cavitaciones evidentes en los estudios radiológicos como una masa cavitada con nivel hidroaéreo en su interior, semejantes a un absceso pulmonar y es el que con menor frecuencia produce metástasis a distancia y por lo tanto es el de mejor pronóstico relativamente comparado con los otros tipos histológicos de cáncer de pulmón. Según la clasificación de la OMS los carcinomas epidermoide-pulmonares se subdividen en papilares, células claras, células pequeñas (similaridad histológica con el microcítico) y basaloide (4).

\section{Caso}

Paciente de sexo masculino, de 59 años, natural y procedente de Villa Rica, Cauca, Colombia, cortero de caña durante la mayor parte de su vida, hipertenso con mala adherencia a la terapia farmacológica, fumador activo de cigarrillo desde los 15 años de edad con un índice promedio de 30 paquetes/año e historial importante de alcoholismo hasta el año anterior a la consulta, sin otros antecedentes relevantes. Relató un cuadro clínico de 8 meses de evolución consistente en dolor en el hemitórax izquierdo y abultamiento progresivo en la región inframamaria ipsilateral, deterioro de su capacidad funcional a causa del dolor hasta el punto de estar incapacitado para laborar desde tres meses antes de la consulta. Tos ocasional no productiva, episodio aislado de hemoptisis, sin disnea, sin fiebre, sin hospitalizaciones previas. Había recibido múltiples esquemas 
analgésicos con respuesta parcial. Refería pérdida de aproximadamente $8 \mathrm{~kg}$ de peso, en los últimos seis meses. Consultó por reagudización del dolor, que se irradiaba a todo el tórax y causaba limitación funcional marcada, y aparición de cambios inflamatorios locales en la lesión descrita previamente.

En la atención inicial enfocaron los hallazgos a un proceso infeccioso de los tejidos blandos del tórax, razón por la cual recibió múltiples esquemas antibióticos con oxacilina, clindamicina, vancomicina y ampicilina-sulbactam por un par de semanas sin aportar mejoría. En la radiografía de tórax se identificó una masa en el tercio medio del hemitórax izquierdo y fue remitido a nuestra institución con sospecha de un absceso pulmonar izquierdo drenado a la pared torácica (figuras 1A y B).

Al ingreso se encontró TA: 135/78 mm $\mathrm{Hg}$, FC: 87 latidos por minuto, T: $36,8^{\circ} \mathrm{C}$, FR: 16 por minuto, $\mathrm{SaO}_{2}$ 93\% $\mathrm{FIO}_{2}$ 21\%. Karnofsky 90. Paciente afrodescendiente, en aceptables condiciones generales, palidez en mucosas, con disminución de masa muscular corporal, sin evidencia de dificultad respiratoria, con algunos ganglios pequeños palpables en la base izquierda del cuello e incremento marcado de medida anteroposterior de este hemitórax por una lesión tumoral con apariencia abscedada a nivel del quinto espacio intercostal con línea axilar anterior izquierda, salida de material purulento en cantidad moderada, muy dolorosa y pétrea a la palpación y cambios inflamatorios locales. A la auscultación pulmonar se halló murmullo vesicular abolido en la mitad inferior del campo pulmonar izquierdo sin anomalías en los ruidos cardiacos, abdomen sin viceromegalias y extremidades sin edemas. El examen neurológico fue normal.

Se ordenó escanografía de tórax en la que se apreció gran masa de aspecto neoplásico localizada en el lóbulo superior izquierdo, la cual estaba en estrecho contacto con el mediastino y pericardio, comprometía los bronquios segmentarios, obliteraba el segmento lingular y continuaba a la pared torácica produciendo destrucción ósea del cuarto arco costal y en menor grado del quinto y sexto, con extensión a los tejidos blandos adyacentes y presencia de
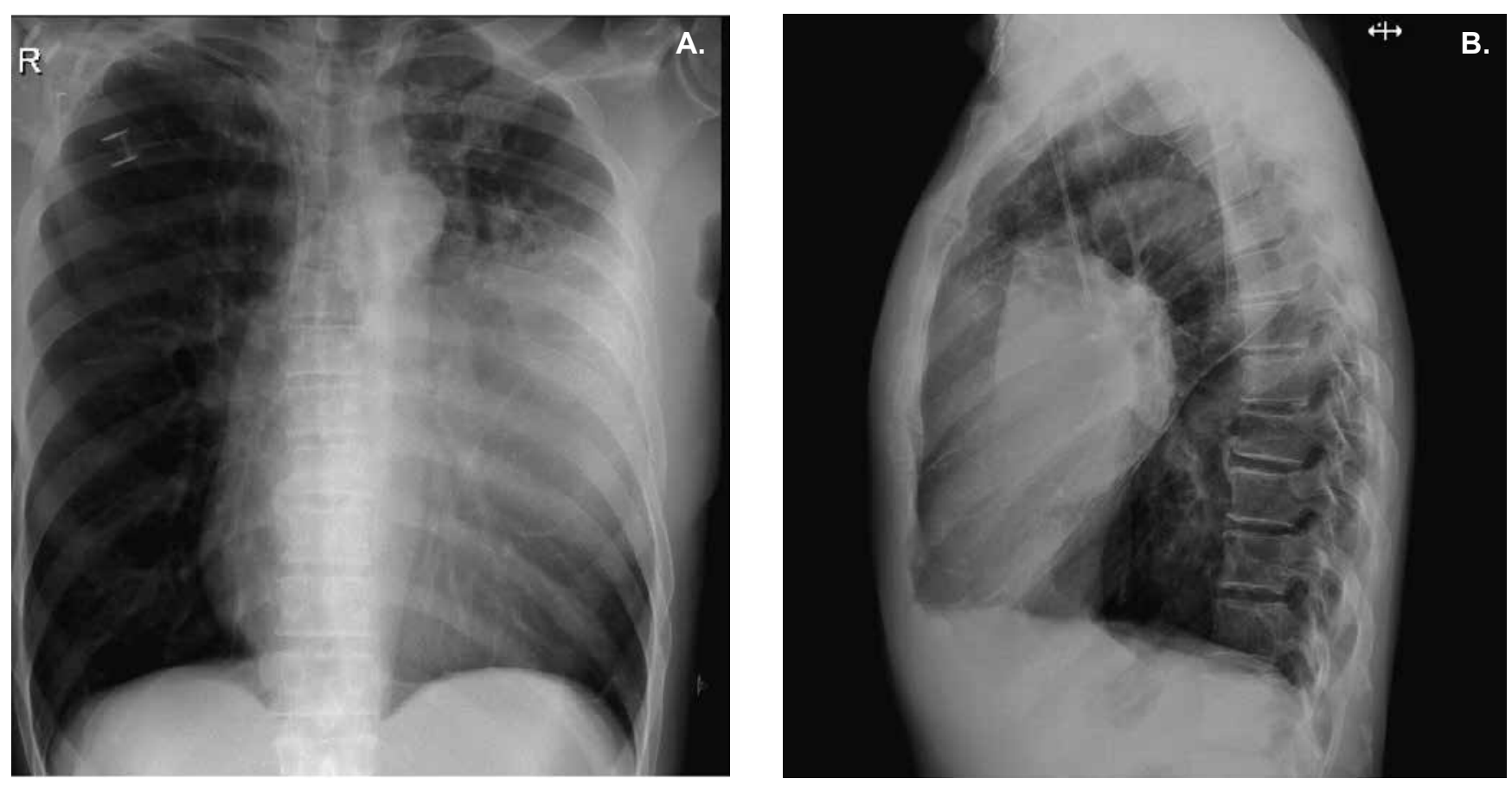

Figura 1. A y B. Radiografía de tórax PA y lateral en la que se aprecia opacidad parenquimatosa en el tercio medio del hemitórax izquierdo con signo de silueta en el borde izquierdo del corazón. 
líquido y burbujas de aire en su interior, de 16, x $13 \times 12, \mathrm{~cm}$ en sentido longitudinal, anteroposterior y transverso respectivamente, tendencia a la cavitación y sin alteraciones parenquimatosas en el campo pulmonar derecho (figuras 2A, B, C, D). Recibió un ciclo corto de antibióticos, se descartó infección por bacterias usuales, Nocardia, Actinomices, hongos y tuberculosis por técnicas de detección molecular y múltiples cultivos negativos en sangre, secreción y muestras histológicas de biopsia percutánea guiada por ultrasonido (figura 3) y transbronquial. Los estudios histopatológicos de las biopsias percutánea,
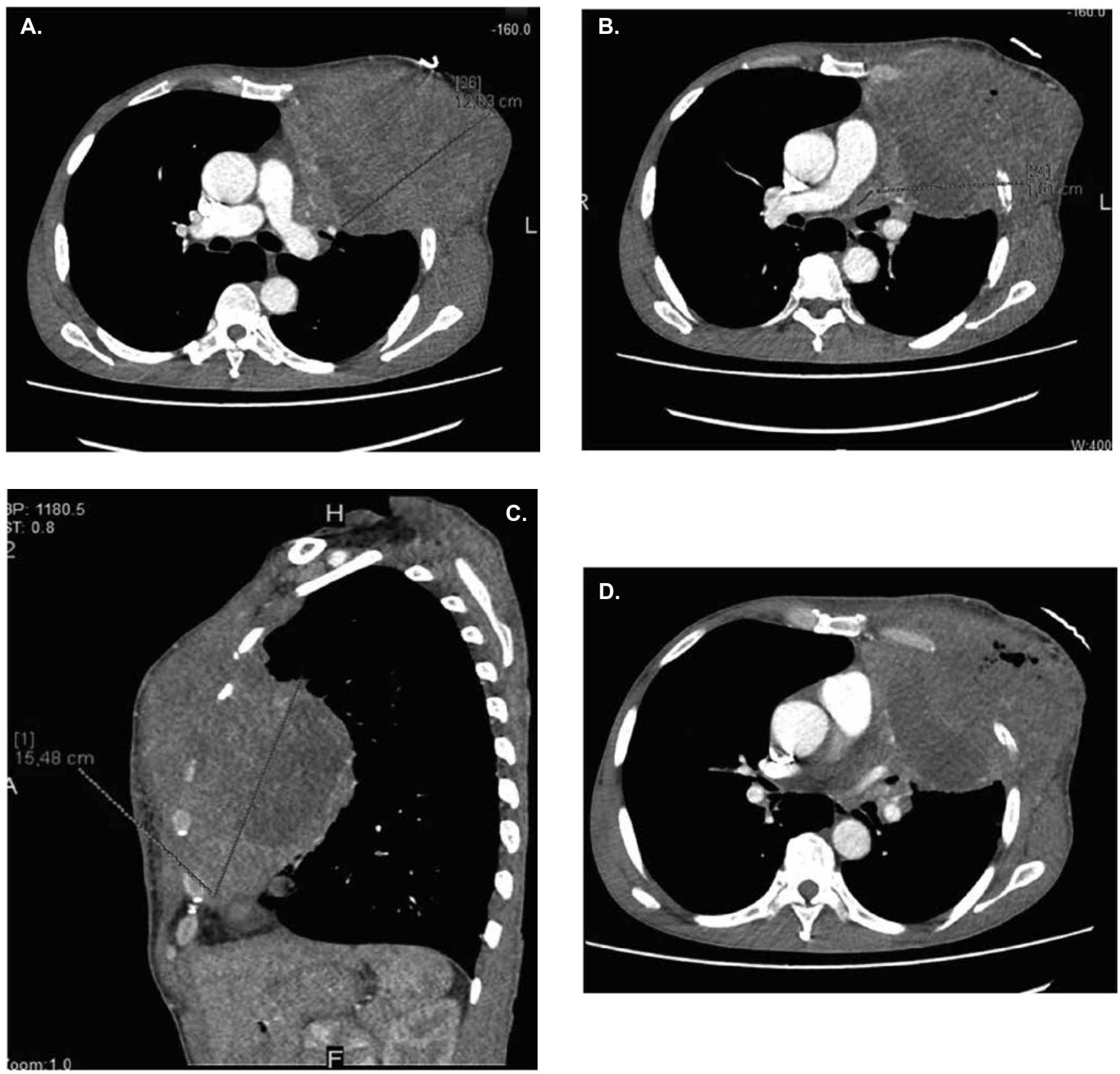

Figura 2. A, B, C, D Aspecto de la escanografía de tórax en la que se aprecia una gran masa en contacto con el mediastino y la arteria pulmonar izquierda, destrucción de los arcos costales, de densidad heterogénea, líquida en la parte central y con burbujas por necrosis o sobreinfección con extensión a los tejidos blandos de la pared. 


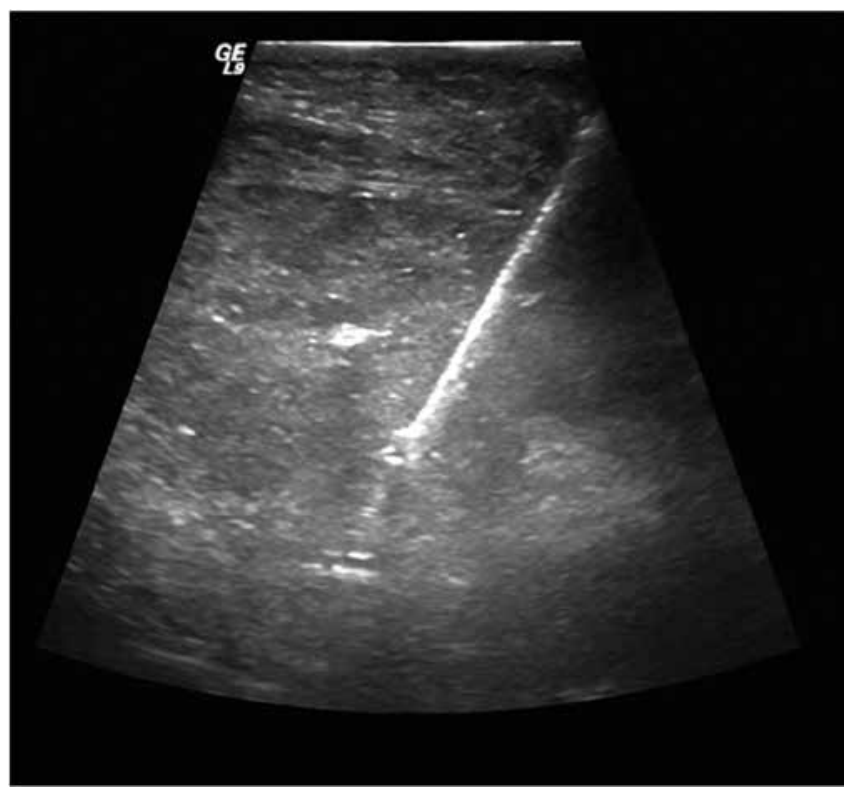

Figura 3. Toma de biopsia percutánea guiada por ultrasonido de la pared del tórax izquierdo.

transbronquial y la citología del lavado broncoalveolar concordaron con patrón histológico de carcinoma escamocelular. Se evaluaron diez fragmentos de tejido con coloración H\&E de los cuales cinco correspondían a queratina, uno a mucosa respiratoria y cuatro a una neoplasia maligna de origen epitelial, compuesta por células escamosas con puentes intercelulares. La técnica de inmunohistoquímica demostró la lesión expresa del gen p63, con coexpresión de CK5/6. No se expresó CK7 o TTF1, además de patrón morfológico y perfil de expresión inmunohistoquímica de carcinoma de células escamosas bien diferenciado (figuras 4 A y B). Se inició quimioterapia con paclitaxel y carboplatino, y se dio de alta para continuar tratamiento ambulatorio.

\section{Discusión}

El éxito en el tratamiento de los tumores de células no pequeñas del pulmón sigue siendo muy pobre, entre otras razones porque el comportamiento biológico del tumor no sigue un patrón definido y usualmente no se puede predecir su desenlace. Hasta ahora, a pesar de la búsqueda activa de marcadores pronósticos nuevos, el estadio tumoral es aun el factor pronóstico más importante; además algunos autores han sugerido que la cavitación dentro de la lesión tumoral puede tener un factor pronóstico negativo significativo (5). Esta última es bastante común en el cáncer de células escamosas; el mecanismo para la formación de las lesiones cavitadas o en proceso de cavitación, como en este caso, no está completamente establecido pero puede ser secundario a isquemia, infección y necrosis con subsecuente expectoración de las masas necróticas a través del bronquio o como en este caso con fistulización a la
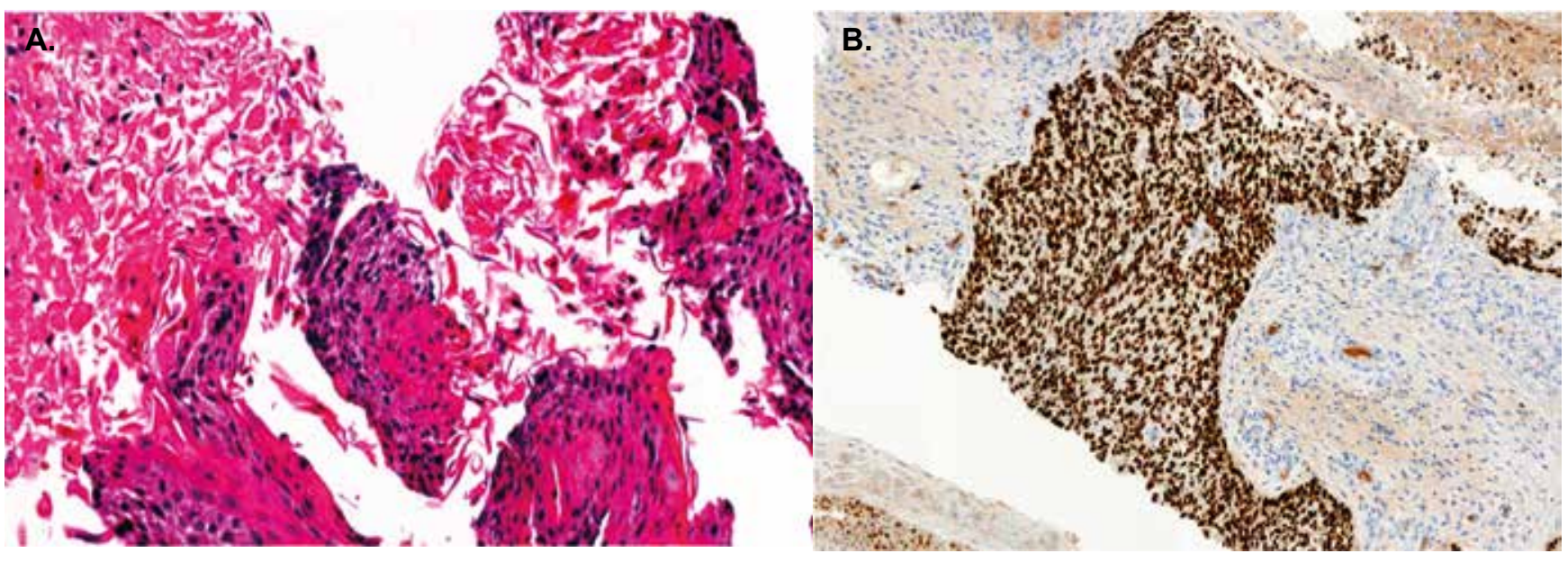

Figura 4. A Carcinoma de células escamosas bien diferenciado, coloración de Hematoxilina \& Eosina. B. Expresión del gen p63 en los núcleos tumorales (inmunohistoquímica). 
pared del tórax, situación extremadamente infrecuente (6). Las lesiones cavitadas tumorales pueden ser interpretadas como abscesos pulmonares y así retardar el diagnóstico durante el tratamiento de los mismos; se sabe además que en un 5 al $15 \%$ de los abscesos pulmonares se encuentra cáncer pulmonar subyacente que predispone a la infección (7), sin tener en cuenta los demás diagnósticos diferenciales como la tuberculosis pulmonar y las infecciones por Nocardia y Actinomicetos.

La fístula a la pared del tórax habla de una enfermedad muy avanzada con pronóstico pobre.

En conclusión, se presentan los hallazgos radiológicos y patológicos de un paciente con una gran masa tumoral de células escamosas, bien diferenciado, acompañado de cavitación, licuefacción y drenaje a través de la pared del tórax.

\section{Bibliografía}

1. Pass HI, Ball D, Scagliotti GV (eds). The IASLC Approach of Thoracic Oncology. Chapter 1. Aurora, CO: International Association for Study of Lung Cancer; 2014. p. 3-13.

2. Herbst RS, Heymach JV, Lippman SM. Lung cancer. N Engl J Med. 2008;359(13):1367-803.

3. Forman D, Bray F, Brewster DH, et al. Cancer incidence in five continents, Vol. X. Lyon, France: International Agency for Research on Cancer; 2013.

4. Travis WD, Brambilla E, Burke AP, et al. WHO, Classification of tumours of the lung, pleura, thymus and heart. 4th edition. Lyon: IARC Press; 2015.

5. Kotodziejski LS, Dyczek S, Duda K, Goralczyk KJ, Wysocki MW, Lobaziewicz W. Cavitated tumor as a clinical subentity in squamous cell lung cancer patients. Neoplasma. 2003;50:66-73.

6. Gasinska A, Kolodziejski L, Niemiec J, Dyczek S. Clinical significance of biological differences between cavitated and solid form of squamous cell lung cáncer. Lung Cáncer. 2005;49:171-9. 